Promoting Responsible Gambling via prevention messages: insights from the evaluation of actual European messages

Aurélie Mouneyrac, Valérie Le Floch, Céline Lemercier, Jacques Py \& Maxime Roumegue CLLE, Université de Toulouse, CNRS, Toulouse, France

Address correspondence to: A. Mouneyrac, University of Toulouse, CLLE-LTC UMR 5263, 5 allée Antonio Machado, 31058 Toulouse Cedex 9, France; aurelie.mouneyrac@univ-tlse2.fr

To cite this article:

Mouneyrac, A., Le Floch, V., Lemercier, C., Py, J., \& Roumegue, M. (2017). Promoting responsible gambling via prevention messages: insights from the evaluation of actual European messages. International Gambling Studies, 1-16. doi:

10.1080/14459795.2017.1350198 


\begin{abstract}
Prevention messages are short sentences supposed to broadcast preventive intentions. Three types of messages are noticeable: messages correcting erroneous beliefs, messages informing about the risks and messages promoting responsible gambling. While messages promoting responsible gambling have alerting results in the literature, they are frequently used in European prevention campaigns. The present study relied on language and semantics' models to evaluate the communicative and preventive values of fourteen messages: seven were actual European prevention messages and seven messages were created for the study. Overall, 339 participants answered to an online questionnaire in which they evaluated the communicative value of one of the messages and then ranked all the messages according to their preventive level. Results showed that messages informing about the risks and messages correcting erroneous beliefs have a higher level of communicative value than messages promoting responsible gambling. Indeed, the latter are judged as more ambiguous and as less preventive than the two other types of messages. As models of conversational pragmatics suggest that ambiguous messages convey at least two interpretations, the article discusses the possibility that individuals comprehend these messages as incentives to control their impulses (prevention) and incentives to control the game (promotion).
\end{abstract}

Keywords: Warning messages; communication; responsible gambling; illusions; control 


\section{Promoting Responsible Gambling via prevention messages: insights from the evaluation of actual European messages}

\section{Introduction}

Problem gambling is the urge to gamble despite negative consequences gambling has on the gambler's life. Problem gamblers face a loss of control over their impulses (Brevers \& Noël, 2013), they hold erroneous beliefs about their ability to control the game and they chase losses inadequately (Fortune \& Goodie, 2012). Accordingly, problem gambling lead to negative consequences: financial problems (e.g. bankruptcy and loans), interpersonal problems (e.g. isolation and neglecting family), and psychosocial problems (e.g. substance abuse and depression) (American Psychiatric Association, 2013). One of the main challenges in gambling area is to implement tools that help gamblers to play without falling into problem gambling.

Prevention was thus developed at three levels: primary, secondary and tertiary (Meyer, Hayer, \& Griffiths, 2009). Primary prevention is aimed at individuals who might be confronted by atrisk activity. Secondary prevention is focused on at-risk individuals. Tertiary prevention is focused on individuals already affected by risky behavior. The heart of primary prevention is to broadcast prevention messages to all individuals having access to the risky activity, whether they already have problems or not (Juanico \& Myard, 2017). They have a critical function to prevent the negative consequences of a risky activity. To this end, a broad range of studies pointed out and evaluated the relevance of different types of messages. For example, some studies examined the effect of fear appeals on compliance with behavior change (for a review, see Tannenbaum et al., 2015). Other researches investigated the effect of adding recommendations in a message on its efficacy (e.g. Brown \& West, 2015), or of the framing of the message (i.e. to present advantages of stopping/adopting an activity, or to present the disadvantages of not stopping/not adopting an activity) (e.g. Gallagher \& Updegraff, 2012). 
Their relative efficacy led to the suggestion that there is not only one type of relevant message, but that their relevance might depend on the risky activity at stake. In gambling, researchers have also used various types of messages in order to fit with the gamblers' needs. For example, the gambler's behavior can be modified by the use of pop-up (vs. static) messages (Auer, Malischnig, \& Griffiths, 2014; Monaghan \& Blaszczynski, 2010), or long and educational messages (Wohl, Christie, Matheson, \& Anisman, 2010). Other studies have shown that gamblers' cognitions and behavior can be modified by messages that aim to enhance self-awareness (Monaghan, 2009), messages that warn about the addictive nature of the games or those that correct erroneous beliefs (e.g. Steenbergh, Whelan, Meyers, May, \& Floyd, 2004). The present article will focus only on the semantic content of messages, namely three types of messages: those that correct erroneous beliefs, those that inform about the risks and those that promote responsible gambling.

Correcting erroneous beliefs is one way to prevent and treat problem gambling (Ferland, Ladouceur \& Vitaro, 2005). Erroneous beliefs are false representations of the causes of an event. In gambling, it is mainly inaccurate thoughts on the laws of games of chance. More particularly, the illusion of control is the perceived ability to control the outcome of the game despite the uncontrollability of the events (Ejova, Delfabbro, \& Navarro, 2013; Langer, 1975). The gambler typically misinterprets random events and thinks he/she can control them. Manifesting illusion of control thus results in the overestimation of the chances to win in regard to what the objective probability would warrant (Langer, 1975). Both problem and non-problem gamblers manifest illusion of control. However, it has been shown that problem gamblers have much more illusion of control than non-problem gamblers (Joukhador, Maccallum, \& Blaszczynski, 2003; Myrseth, Brunborg, \& Eidem, 2010).

Correcting erroneous beliefs is based on the idea that fighting erroneous beliefs limits at-risk behaviors. When they are corrected, individuals adopt a more appropriate behavior (Weiner, 
Osborne, \& Rudolph, 2011; Kouabenan \& Ngueutsa, 2015). Correcting erroneous beliefs is in fact already used in cognitive therapy as a strategy to treat problem gambling (Ladouceur \& Walker, 1996). Multiple studies have also shown that correcting erroneous beliefs by prevention messages is relevant to prevent problem gambling (Benhsain, Taillefer, \& Ladouceur, 2004; Cloutier, Ladouceur \& Sévigny, 2006; Floyd, Whelan, \& Meyers, 2006; Jardin \& Wulfert, 2009; Martinez, Le Floch, Gaffié, \& Villejoubert, 2011; Steenbergh et al., 2004). For example, messages reminding the predominance of chance on the outcome of the game in a session of gambling limit risk-taking of the gamblers (Martinez et al., 2011). Broadcasting messages that aim to correct erroneous beliefs (e.g. Remember that it is a game of chance) seems to be a good way to prevent problem gambling. Despite the literature showing the relevance of these messages to prevent problem gambling, we did not find any of them in the European gambling operators we reviewed.

Below are some examples of European prevention messages we found:

1) Do not gamble as far as dependency (Germany, Lotto 6 aus 49)

2) Gambling can cause a dependency (Italy, Lottomatica)

3) Remain the master of the game (FDJ, France)

4) Gamble in a balanced way (Belgium, Loterie Nationale)

5) So that gambling remains a game (Switzerland, Loterie Romande)

6) Gamble responsibly (Spain, Loterías y Apuestas del Estado)

7) Keep it fun, stay in control (United Kingdom, National Lottery)

Among them, messages 1 and 2 are messages oriented towards information about the risks, while messages 3 to 7 are messages oriented towards the promotion of responsible gambling. Prevention campaigns informing about the risks (message 1 and 2) are based on the idea that the more individuals are informed about the risks associated with the at-risk activity, the more they are willing to stop their hazardous behavior. This effect has been showed in tobacco 
consumption (Hammond, Fong, Mc Neill, Borland, \& Cummings, 2006; Rothman \& Kiviniemi, 1999; Song et al., 2009). A study on gambling support these results, showing that individuals effectively report a higher knowledge of the risk after exposure to these messages (Steenbergh et al., 2004). These results suggest that the strategy consisting in informing about the risks in effective for problem gambling prevention messages.

Prevention campaigns promoting responsible gambling (messages 3 to 7) are based on the idea that individuals can voluntarily adopt a safe behavior when they are reminded of their responsibility (Parke, Harris, Parkes, Rigbye, \& Blaszczynski, 2015). It is most important in gambling, where problem gamblers face a loss of control concerning money and time spent (Bergen, Newby-Clark, \& Brown, 2012). Numerous studies thus stressed the relevance of tools that remind gamblers to set limits of time and money (e.g. Auer, Malischnig, \& Griffiths, 2014; Kim, Wohl, Stewart, Sztainert, \& Gainsbury, 2014; Monaghan \& Blaszczynski, 2010; Steenbergh et al., 2004; Wood \& Wohl, 2015). These tools can be, for example, a clock within sight of the gambler, a pause or messages alerting to the time or money spent (Blaszczynski, Gainsbury, \& Karlov, 2014). These messages are called "Responsible gambling prevention messages": they specifically remind the time and money spent, directly implement the principles of responsible gambling, or encourage self-awareness (Auer \& Griffiths, 2015; Monaghan \& Blaszczynski, 2010). An example of self-appraisal messages is "Do you know how long you have been playing?". This type of message is particularly relevant in helping individuals to limit their gambling behaviors (Monaghan \& Blaszczynski, 2010). However, the messages broadcasted by European gambling operators (messages 3 to 7) are different. Instead of reminding gamblers to set limits, they are specifically oriented toward promoting the concept of responsible gambling (we will call them "Prevention messages promoting responsible gambling"). Little is known about the comprehension of these messages. Interestingly, one study alerts to the potential negative 
effect of this type of messages (Papineau, Boisvert, Chebat, \& Suissa, 2012). In their experiment, the authors evaluated the prevention message Mise sur Toi (Bet on Yourself), which was at the time of the study the slogan of the Quebec National Prevention Campaign against problem gambling (Papineau et al., 2012). They have shown that this prevention message was comprehended either as preventive ("gamble less") or as an incentive to gamble ("gamble more"). What the message conveyed - its semantic content - was subject to two interpretations and thus responsible for its bad communicative value. The rationale behind these two possible interpretations is that individuals would be subject to the illusion of control (Langer, 1975). In this perspective, individuals would interpret the message as an incentive to control the game. It is possible that this effect is not limited to the message Bet on yourself, but also applies to all the messages that promote responsible gambling. It is thus of main importance to test if the preventive intentions of actual preventions messages are correctly broadcast.

To sum it up, at least three types of messages can be used to prevent problem gambling: correcting erroneous beliefs, informing on the risks and promoting responsible gambling. There is much evidence in favor of the relevance of prevention messages correcting erroneous beliefs and informing on the risks. However, there is evidence that the preventive intentions of messages promoting responsible gambling might not be comprehended.

Comprehension of the preventive intention of a prevention message depends on the level (from very low to very high) of its communicative value (ARJEL, 2013; Laughery \& Wogalter, 2014; Rogers, Lamson, \& Rousseau, 2000). The communicative value of a message is the extent to which the message can improve comprehension, the ease of its retrieval, and its perceived relevance to the context (Chomsky, 1965; Fodor \& Garrett, 1967; Gallardo, 2005; Grice, 1975; Johnson-Laird, 1977, 1983; Le Floch, 2008; Sperber \& Wilson, 1986). The communicative value of a message is evaluated according to three criteria of 
communication: (1) the grammatical value of the message, (2) its respect of Grice's maxims, (3) and its relevance to the context.

First, the grammatical value of a message is the extent to which the sentence is produced and interpreted with regard to the rules of relevant grammar (Chomsky, 1965). Regularities of grammar help the hearer delineate the meaning of the message. For example, a message that uses the present tense describes something that happens, or might happen, right now in relation to the actual situation. Hearers comprehend what is said in the message because of the use of the present tense. Thus, the more a message is grammatically correct, the more its meaning will be recalled and reconstructed (Fodor, 1983; Fodor \& Garrett, 1967; Ratcliff, 1987). Non-grammaticality, although not exclusively responsible, leads to the production of a multitude of interpretations of the message and misunderstandings (Chomsky, 1965). Second, a conversation takes place with specific interlocutors and the comprehension of the intended meaning of each interlocutor depends on mutual cooperation. Grice's maxims (also called conversational maxims) are rules guiding conversation between the speaker and the hearer. The speaker follows these rules in order to improve the hearer's comprehension, and these rules guide the hearer to interpret the message. Therefore, the interlocutors work together to optimize the correct transmission of the intended meaning of the message (Wänke, 2007). There are four Grice's maxims: the maxims of quantity, quality, relation and manner (Grice, 1975). The maxim of quantity states that the message has to be informative but not more than necessary (e.g. a child will not explain who his/her father is to his/her mother, but he/she will have to explain it to a new friend). The maxim of quality calls for the message to be truthful and reliable (e.g. the hearer expects the speaker to talk only about what he/she knows to be true and for which he/she has proof). The maxim of relation requires the message to give relevant information (e.g. a speaker talking about the blue sky in a work meeting does not help the group to solve the work task). Finally, the maxim of manner requires the speaker to 
be clear and avoid obscurity and ambiguity (e.g. the use of brief and simple sentences is better than obscure and long sentences) (Grice, 1975). Third, the context of the communication has an important role in communication as it gives cues indicating which interpretation to choose among all the possible interpretations of the message. In a discourse, relevance to the context decreases the cognitive demands on the interlocutors by directing the interpretation to give to the message (Sperber \& Wilson, 1986).

In sum, the more a message is grammatically correct, informative, truthful, clear and relevant, the more it will facilitate comprehension and the correct transmission of the intended meaning. All these criteria share an intimate link to increase the comprehension of the intended meaning of the message. Conversational pragmatics have already been used to enhance the communicative value of interventions (e.g. in ordinary communications, Bazzanella \& Damiano, 1999; in persuasive marketing, Cheung, 2010; in medicine support, Gallardo, 2005; and in safety-critical talks, Andrén et al., 2010). However, to our knowledge, no study evaluated the communicative value of prevention messages. Prevention messages with a high communicative value might increase their chances of being comprehended, and thus to be perceived as preventive.

The present study aimed to evaluate the communicative and preventive values of actual European prevention messages. A corpus of 14 prevention messages was tested. Seven were European problem gambling prevention messages currently used at the time of the data collection and seven were newly created messages. We thus tested three types of messages: messages promoting responsible gambling (five actual messages), messages informing about the risks (two actual messages) and messages correcting erroneous beliefs (seven messages created for the experiment). We hypothesized that prevention messages correcting erroneous beliefs and prevention messages informing on the risks would better communicate preventive intentions than messages promoting responsible gambling. 


\section{Method}

\subsection{Sample}

Participants were recruited on the social network Facebook ®. The experimenter broadcasted advertisements for this study mainly to groups of students of French universities. Participants were asked to answer a brief questionnaire for a study evaluating gambling prevention messages. The experimenter also explained that their participation was free and anonymous. The study was broadcasted using Qualtrics online survey software ®. Initially, 847 individuals participated in the study from 27 December 2013 to 20 March 2014. We excluded $59.98 \%$ of the participants from the analysis because of incomplete data $(n=508)$. This dropout rate is consistent with the literature, which states that online questionnaires are highly subject to abandon (O’Neil, Penrod, \& Bornstein, 2003). Finally, the questionnaires of 339 participants were used in our analysis. The population ranged in age from 18 to 70 years old, and $70.2 \%$ were between 18 and 25 years. The majority of the participants were women $(72.6 \%)$. Fifty one percent of the respondents reported having already gambled in their life.

\subsection{Instruments}

\subsubsection{Corpus of prevention messages}

The corpus is composed of 14 messages allocated to 3 types of messages: promoting responsible gambling, informing about the risks or correcting erroneous beliefs (Table 1). We first searched for the prevention messages broadcasted by the national lotteries in Europe. We selected the messages that were the most accessible to the gamblers: on the front page of the gambling operator's website or in their brochures (physical supports) ${ }^{1}$. As no messages

\footnotetext{
${ }^{1}$ At this stage of the study, we aimed to collect messages. Therefore, we did not aim to systematically reference prevention messages in Europe. Existing messages used here cannot therefore be considered as an inventory of practices in Europe.
} 
correcting erroneous beliefs were found in the list of messages collected, we created them.

These messages are similar to those of Cloutier and colleagues' study (2004).

Table 1. Corpus of prevention messages

English translation Semantic content

\section{Actual European prevention messages}

\begin{tabular}{|c|c|}
\hline $\begin{array}{l}\text { Remain the master } \\
\text { of the game }\end{array}$ & $\begin{array}{l}\text { Responsible } \\
\text { gambling }\end{array}$ \\
\hline $\begin{array}{l}\text { Gamble in a } \\
\text { balanced way }\end{array}$ & $\begin{array}{l}\text { Responsible } \\
\text { gambling }\end{array}$ \\
\hline $\begin{array}{l}\text { So that gambling } \\
\text { remains a game }\end{array}$ & $\begin{array}{l}\text { Responsible } \\
\text { gambling }\end{array}$ \\
\hline Gamble responsibly & $\begin{array}{l}\text { Responsible } \\
\text { gambling }\end{array}$ \\
\hline $\begin{array}{l}\text { Keep it fun, stay in } \\
\text { control }\end{array}$ & $\begin{array}{l}\text { Responsible } \\
\text { gambling }\end{array}$ \\
\hline $\begin{array}{l}\text { Do not gamble as far } \\
\text { as dependency }\end{array}$ & $\begin{array}{l}\text { Information about } \\
\text { the risks }\end{array}$ \\
\hline $\begin{array}{l}\text { Gambling can cause } \\
\text { a dependency }\end{array}$ & $\begin{array}{l}\text { Information about } \\
\text { the risks }\end{array}$ \\
\hline
\end{tabular}

France

(FDJ)

Belgium

(Loterie Nationale)

Switzerland

(Loterie Romande)

Spain

(Loterías y Apuestas

del Estado)

\section{United Kingdom}

(National Lottery)

Germany

(Lotto 6 aus 49)

Italy

(Lottomatica)

\section{Original language French translation}

Restez maître du jeu Restez maître du jeu

Jouez de manière

Jouez de manière

équilibrée

équilibrée

Pour que le jeu

Pour que le jeu reste un jeu

Jouez responsable

Juego Seguro
Keep it fun, stay in control

Spiel nicht bis zur sucht

Il gioco può causare Jouer peut causer une dipendenza patologica dépendance est acceptable dépendance

\section{Created prevention messages}

Don't forget that thisErroneous beliefs is only due to chance

Remember that it is Erroneous beliefs a game of chance

Don't forget that youErroneous beliefs have no control over

chance

There is no strategy Erroneous beliefs to fight against

chance

You don't control anything in a game

Erroneous beliefs of chance

This game only depends on chance

Erroneous beliefs

Chance is the only Erroneous beliefs decisive factor of this game N'oubliez pas que c'est uniquement du hasard

Jouer avec modération

Ne jouez pas jusqu'à la

Souvenez-vous que c'est un jeu de hasard

N'oubliez-pas que le hasard ne se maîtrise pas

Aucune stratégie ne permet de lutter contre le hasard

Vous ne maîtrisez rien dans le jeu de hasard

Ce jeu est soumis uniquement au hasard

Le hasard est le seul facteur déterminant de ce jeu 


\subsubsection{Questionnaire on the communicative and preventive value of the messages}

The questionnaire consisted of two parts: in part A, the participants had to evaluate the communicative value of one message (inter-group plan). In part B, the participants had to rank the 14 messages from the most to the least preventive (intra-subject plan).

In part A, the participants evaluated only one message that was randomly assigned. Fourteen versions of the questionnaire were constructed, each one presenting a different message. An inter-group plan permitted a non-biased evaluation of the communicative value of the message, independently of the other messages we had to test for this study. Thus the participants rated one message based on criteria of conversational pragmatics (Fodor, 1983; Fodor \& Garrett, 1967; Grice, 1975; Ratcliff, 1987; Sperber \& Wilson, 1986). This questionnaire consisted of 10 items that were rated on a Likert scale going from $0 \%$ (not at all) to $100 \%$ (completely). Among the 10 items, one concerned grammaticality ( "this statement is grammatically correct"), one concerned relevance ("this statement is relevant in the context of a message warning about the risks associated with gambling”) and the remaining eight dealt with Grice's maxims (quantity: “There is enough information in this statement to prevent the risk of problem gambling", "There is unnecessary information in this statement" (reversed item); quality: "This statement is credible to prevent the risk of problem gambling"; manner: "this statement is ambiguous" (reversed item), "In a context of gambling, this statement is clear and comprehensible to me"; relation: "I would not be surprised to hear this statement, whatever the situation", "I think that this statement is consistent", "I think that this statement is often heard"). Each of the 14 problem gambling prevention messages was evaluated by 20 to 38 participants. Cronbach's alpha was $\alpha=.718$. The dependent variable of communicative value was obtained from the mean score on all the criteria of conversational pragmatics. 
Part B consisted of one item. The participants had to rank all 14 messages from the most preventive (rank 1) to the least (rank 14). Each message was thus evaluated in relation to the 13 other messages. The intra-subject plan used for this part of the questionnaire evaluated the preventive value of the messages in relation to the other ones.

\subsubsection{Attention filter}

An item was added to part A of the questionnaire to ensure that participants carefully read the instructions. To that end, they were asked the following question "In order to verify that you are effectively reading the questions, please move the cursor to $50 \%$ (on a scale from 0 to $100 \%) "$. All the participants included in the present sample fulfilled this condition.

\subsubsection{Socio-demographic questionnaire}

Socio-demographic information was collected (frequency of gambling, age, gender, profession).

\subsection{Procedure}

The present study was conducted when there was no Ethics Committee in the University of Toulouse to examine non-interventional studies. To insure the respect of ethical principles, we referred to the code of conducts edicted by the French Psychological Society (http://www.sfpsy.org/). Participants were informed that the scope of the study was gambling prevention messages. They were informed that the study consisted of some questions and that participation was voluntary. No incentive was given for the study. Participants could stop their participation anytime. The study was anonymous as we did not collect any information that could identify them. All participants were informed of the confidentiality and the anonymity of their responses, and agreed to give their free and informed consent. The 
participants that gave their written informed consent to participate were directed to the questionnaire and the others were dismissed. After giving socio-demographic information, the participants were randomly assigned to one of the 14 conditions in part A of the questionnaire. Finally, they had to complete part B of the questionnaire by ranking all the 14 messages from the most to the least preventive. All the measures were completed online. This procedure was in accordance with the 1964 Helsinki declaration and its later amendments or comparable ethical standards.

\section{Results}

\subsection{Analysis}

The independent variable was the type of message (messages correcting erroneous beliefs, informing on the risks and promoting responsible gambling). We first examined its effect on the evaluation of the communicative value (part A of the questionnaire) with ANOVAs. Second, we analysed its effect on the preventive value of the message (part B of the questionnaire) with Friedman's non-parametric test. Third, we verified the association between the communicative value (part A) and the preventive value (part B). The communicative value was a continuous variable (100\% being the best communicative value and $0 \%$ the worst) and preventive value was an ordinal variable ( 1 being the best preventive value and 14 the worst). Non-parametric tests ( $\chi^{2}$ and Spearman Rho) were conducted. All the analyses were considered as significant as their $p$-values were less than $5 \%$.

\subsection{Communicative value}

The type of the messages influenced the communicative value $(F(2,339)=6.89, M S e=$ 730.76, $p<.001, \eta^{2}=.039$, see Table 2). A post hoc test (Tukey) showed that messages promoting responsible gambling had the lowest communicative value $(M=47.49 ; S D=$ 28.07), as compared to messages informing about the risks $(M=62.26, S D=27.20)$ and messages correcting erroneous beliefs $(M=57.23, S D=26.22)($ both $p<0.5)$. 
Table 2. Participants' judgment about the ability of the messages to communicate their intentions (degree of communicative value) and their preventive value (mean rank from the first place to the fourteenth)

\begin{tabular}{lcc}
\hline \multicolumn{1}{c}{ Messages } & $\begin{array}{c}\text { Communicative } \\
\text { value } \\
\text { M }(\boldsymbol{S D})\end{array}$ & $\begin{array}{c}\text { Perceived } \\
\text { preventive value } \\
\text { Mean rank }\end{array}$ \\
\hline Messages informing about the risks & $\mathbf{6 2 . 2 6}(\mathbf{2 7 . 2 0})$ & $\mathbf{1 . 6 1}$ \\
Gambling can cause a dependency $(n=20)$ & $69.28(19.59)$ & 4.78 \\
Do not gamble as far as dependency $(n=26)$ & $56.87(31.14)$ & 6.96 \\
Messages correction erroneous beliefs & $\mathbf{5 7 . 2 3}(\mathbf{2 6 . 2 2})$ & $\mathbf{2 . 1 1}$ \\
You don't control anything in a game of chance $(n=26)$ & $67.62(26.04)$ & 6.48 \\
There is no strategy to fight against chance $(n=22)$ & $62.39(20.22)$ & 6.89 \\
This game only depends on chance $(n=21)$ & $60.24(29.28)$ & 8.33 \\
Don't forget that you have no control over chance $(n=20)$ & $58.13(24.35)$ & 6.47 \\
Remember that it is a game of chance $(n=26)$ & $56.35(25.03)$ & 7.89 \\
Chance is the only decisive factor of this game $(n=27)$ & $50.63(26.89)$ & 8.37 \\
Don't forget that this is only due to chance $(n=28)$ & $47.84(27.53)$ & 7.68 \\
Messages promoting responsible gambling & $\mathbf{4 7 . 4 9 ( 2 8 . 0 7 )}$ & $\mathbf{2 . 2 8}$ \\
So that gambling remains a game $(n=20)$ & $64.25(24.20)$ & 8.19 \\
Keep it fun, stay in control $(n=38)$ & $46.79(29.55)$ & 9.57 \\
Remain the master of the game $(n=21)$ & $43.88(28.59)$ & 7.03 \\
Gamble responsibly $(n=20)$ & $43.50(27.37)$ & 7.13 \\
Gamble in a balanced way $(n=24)$ & $41.15(25.45)$ & 9.24 \\
\hline
\end{tabular}

Note. For the communicative value scale, higher scores are indicative of a high communicative value. Conversely, for the preventive value ranks, a lower score indicates a high perceived preventive value.

In order to explore the impact of the type of message on each criterion of conversational pragmatics, we conducted 10 analyses of variance (ANOVA) with the scores of each item of conversational pragmatics as the dependent variables.

The analysis revealed a main effect of type of messages on Comprehension and clarity of the message $\left(F(2,339)=5.354\right.$, MSe $\left.=1156.21, p<.005, \eta^{2}=.031\right)$ and on Ambiguity of the message $\left(F(2,339)=6.47\right.$, MSe $\left.=1405.23, p<.002, \eta^{2}=.037\right)$. Messages promoting responsible gambling were judged to be less comprehensible and clear $(M=52.39, S D=$ 35.73) than messages informing about the risks $(M=69.17, S D=29.96 ; p<.013)$ and 
messages correcting erroneous beliefs $(M=62.86, S D=33.73 ; p<.026)$. Moreover, messages promoting responsible gambling were more ambiguous $(M=59.43, S D=37.28)$ than messages informing about the risks $(M=42.74, S D=36.00 ; p<.028)$ and messages correcting erroneous beliefs $(M=44.66, S D=38.21 ; p<.003)($ Table 2$)$. All other comparisons between messages informing about the risks and messages correcting erroneous beliefs were not significant (all $p$-values $>.05)$.

\subsection{Preventive value}

A Friedman test was conducted on the mean rank of the type of messages $\left(\chi^{2}(2)=84.83, p<\right.$ $.001)$. Messages informing about the risks were the most preventive (mean rank $=1.61$ ), followed by messages correcting erroneous beliefs (mean rank $=2.11$ ) and messages promoting responsible gambling (mean rank $=2.28$ ).

\subsection{Link between the communicative and preventive values}

The communicative value was correlated with the preventive value of the message $\left(r_{s}=-.556\right.$, $p<.05)$. Messages with the highest communicative values were the most preventive, and vice versa. A negative correlation was due to opposite codification of the communicative and preventive value: a high communicative value corresponded to a high value of the message while a high rank on the preventive value corresponded to a low value (the message with the lowest rank was codified as the fourteenth).

The ranks given to the types of messages according to their communicative and preventive values did not differ significantly $\left(\chi^{2}(1)=0.117, n s\right)$. Messages informing about the risks had the highest communicative value $(M=62.26, S D=27.20)$ and the highest preventive value (mean rank $=1.61)$. Messages promoting responsible gambling had the lowest communicative value $(M=47.49, S D=28.07)$ and the lowest preventive value (Mean rank $=2.28)$. Messages correcting erroneous beliefs fell between them on both their communicative value $(M=57.23$, $S D=26.22)$ and their preventive value (Mean rank $=2.11)$. 


\section{Discussion}

The purpose of the current study was to evaluate three types of prevention messages (i.e. messages correcting erroneous beliefs, messages informing about the risks and those promoting responsible gambling) by using the criteria of conversational pragmatics. Specifically, we sought to examine whether actual European messages were correctly understood as prevention messages. First, our results showed that both the preventive and communicative values of messages informing about the risks and messages correcting erroneous beliefs were better than for messages promoting responsible gambling. Messages promoting responsible gambling were found to be ambiguous.

Importantly, this study demonstrated the link between communicative and preventive values. A message that communicates well is considered as more preventive than a message that communicates badly. This result is consistent with both the literature on prevention messages (Laughery \& Wogalter, 2014; Rogers et al., 2000) and the recommendations of the French Regulatory Authority of Gambling (ARJEL, 2013). The results obtained highlight the need for further research on the communicative value of prevention messages. Indeed, the vast majority of studies on prevention messages have focused on their preventive value (Auer \& Griffiths, 2015; Chaiken \& Trope, 1999; May, Whelan, Meyers, \& Steenbergh, 2005; Petty \& Cacioppo, 1986; Rothman, Bartels, Wlaschin, \& Salovey, 2006). The preventive value of a message is its ability to modify attitudes and/or behaviors. In the present study, we showed that considering the communicative value of the messages can give helpful insights in the evaluation of prevention messages.

Our results support the fact that messages informing on the risks and messages correcting erroneous beliefs effectively communicate preventive intentions. These results are consistent with the literature, which shows that these messages are able to, respectively, increase the knowledge on the risks of gambling and correct erroneous beliefs (Steenbergh et al, 2004). 
Thus, these two semantic contents appropriately broadcast preventive intentions. These results encourage further research on the use of these messages.

Results also showed that individuals perceived messages promoting responsible gambling (e.g. Remain the master of the game in France and Keep it fun, stay in control in the United Kingdom) as less preventive than messages informing about the risks (e.g. Gambling can cause a dependency) and messages correcting erroneous beliefs (e.g. Remember that it is a game of chance). These results are consistent with the results of Papineau and colleagues (2012) who found that the Quebec National Prevention Campaign (Bet on yourself) was comprehended as an incentive to gamble, which was the complete opposite of the preventive intentions of this campaign. The present findings offer a structural explanation for this phenomenon by identifying the semantic content "responsible gambling" as problematic. The present study enriches the findings of Papineau and colleagues (2012) by using a much larger and representative corpus of prevention messages. This allowed us to identify the concept of responsible gambling as a risk factor for the ambiguity of prevention messages. The example of self-appraisal messages, which could be considered as part of a responsible gambling strategy, are in fact very different from messages promoting responsible gambling. The fact that self-appraisal messages are directly oriented towards reminding time or money spent might prove to be the key components of their effectiveness (Monaghan \& Blaszczynski, 2010). Indeed, our study has shown that messages that only remind the concept of responsible gambling in prevention messages are not appropriate to communicate preventive intentions. In this perspective, our results suggest that self-appraisal messages cannot be considered to be messages promoting responsible gambling.

Our results indicate that messages promoting responsible gambling specifically violated Grice's maxim of manner (i.e. they are ambiguous). More importantly, this supports the idea that multiple interpretations of these messages were available to the reader. The reader might 
associate responsible gambling with: 1) the possibility to control his/her risky behaviors and limit them when necessary (Parke et al., 2015), and 2) the possibility to control the risky situation, which corresponds exactly to the illusion of control (Langer, 1975). Research has now to determine whether individuals rely or not on the illusion of control (Ejova et al., 2013; Langer, 1975) to interpret messages promoting responsible gambling.

The fact that prevention messages promoting responsible gambling are ambiguous is alarming. By promoting responsible gambling, public policies and gambling operators aim to help gamblers to better control their behavior. However, in practice, it is possible that these messages do not fulfil their intended goal. Indeed, we showed that these messages are ambiguous and do not communicate what they are supposed to. The best-case scenario is that these messages have no negative impact, but under worst-case intake conditions, these messages could act as gambling promotion messages. We need more studies to determine the presence of illusion of control in these messages, and to evaluate its impact on the gambler's risk taking and perseverance. These studies will make it possible to inform public policies and warn gambling operators. The present study opens a new field of research about prevention messages promoting responsible gambling.

This study has some limitations. First, the corpus of prevention messages used in this study was relatively small, not representative of all types of prevention messages and only involved problem gambling prevention. Indeed, we chose to evaluate actual European messages in order to give direct, practical insights to public policies. Following studies should use a more standardized and pretested corpus of messages to ascertain the generalizability of the results. Second, the sample was not representative of all European countries as recruitment was undertaken only in France. As a result, participants could have been familiar with some actual messages (they were probably familiar with Remain the master of the game) but not with foreign and created messages. Participants participated voluntarily, without incentives, 
which could entail self-selection bias. However, we randomly distributed the conditions. As such, the differences found between the conditions cannot be explained by this bias. Third, we did not evaluate whether a message is effective or not. It could be argued that messages evaluated as bad communications could still be effective in preventing problem gambling. For instance, the French message Remain the master of the game, known as a prevention message by the French population, could be considered conventionally as a prevention message. Thus, this message could still have a positive impact on the gambler's behavior. Further evaluation of prevention messages should examine the ability to retrieve the message and its positive, negative or neutral consequences on behaviors. The results obtained encourage pursuing the evaluation of actual prevention messages used in more countries, other risky domains and with more representative samples.

\section{Conclusion}

Primary prevention campaigns aim to preserve and promote good health through proactive interventions such as information campaigns promoting individual's responsible control of gambling (Meyer et al., 2009). However, the misunderstandings observed in the literature (Papineau et al., 2012) and our results confirm the necessity to increase the effectiveness of these messages to communicate preventive intentions. The preventive intentions of messages that inform on the risks of gambling and messages that correct erroneous beliefs are correctly grasped. However, we showed that actual prevention messages such as the French message Remain the master of the game, the Swiss message So that gambling remains a game, the Spanish message Gamble responsibly, the British message Keep it fun, stay in control and the Belgian message Gamble in a balanced way have little communicative and preventive value. Consequently, a more systematic evaluation of the comprehension of actual prevention messages is required. Our results underline two important 
aspects that need to be studied in prevention messages: first, particular attention should be given to the comprehension of the messages and second, the concept of responsible gambling in prevention messages might be problematic. An approach that focuses on reminding time and money spent (i.e. self-appraisal messages: "Do you know how long you have been playing?") is more promising for public policies than prevention campaigns that only remind the concept of responsible gambling.

\section{References}

American Psychiatric Association. (2013). Diagnostic and statistical manual of mental disorders (5th ed.). Arlington, VA: American Psychiatric Publishing.

Andrén, M., Sanne, J. M., \& Linell, P. (2010). Striking the balance between formality and informality in safety-critical communication: Train traffic control calls. Journal of Pragmatics, 42(1), 220-241. http://doi.org/10.1016/j.pragma.2009.05.022

ARJEL (2013). Lutter contre le jeu excessif ou pathologique [Fight against excessive or pathological gambling] (Working paper). Retrieved from the ARJEL website: http://www.arjel.fr/IMG/pdf/20130426-addiction.pdf

Auer, M., \& Griffiths, M. D. (2015). Testing normative and self-appraisal feedback in an online slot-machine pop-up in a real-world setting. Frontiers in Psychology, 6. http://doi.org/10.3389/fpsyg.2015.00339

Auer, M., Malischnig, D., \& Griffiths, M. D. (2014). Is « pop-up » messaging in online slot machine gambling effective as a responsible gambling strategy? Journal of Gambling Issues, 29, 1-10. https://doi.org/10.4309/jgi.2014.29.3

Bazzanella, C., \& Damiano, R. (1999). The interactional handling of misunderstanding in everyday conversations. Journal of Pragmatics, 31(6), 817-836.

http://doi.org/10.1016/S0378-2166(98)00058-7 
Benhsain, K., Taillefer, A., \& Ladouceur, R. (2004). Awareness of independence of events and erroneous perceptions while gambling. Addictive Behaviors, 29(2), 399-404. http://doi.org/10.1016/j.addbeh.2003.08.011

Bergen, A. E., Newby-Clark, I. R., \& Brown, A. (2012). Low Trait Self-Control in Problem Gamblers: Evidence from Self-Report and Behavioral Measures. Journal of Gambling Studies, 28(4), 637-648. http://doi.org/10.1007/s10899-011-9274-9

Blaszczynski, A., Gainsbury, S., \& Karlov, L. (2014). Blue Gum Gaming Machine: An Evaluation of Responsible Gambling Features. Journal of Gambling Studies, 30(3), 697-712. https://doi.org/10.1007/s10899-013-9378-5

Brevers, D., \& Noël, X. (2013). Pathological gambling and the loss of willpower: a neurocognitive perspective. Socioaffective Neuroscience \& Psychology, 3(0): 21592 https://doi.org/10.3402/snp.v3i0.21592

Brown, S. L., \& West, C. (2015). Sequencing the threat and recommendation components of persuasive messages differentially improves the effectiveness of high- and lowdistressing imagery in an anti-alcohol message in students. British Journal of Health Psychology, 20(2), 324-340. https://doi.org/10.1111/bjhp.12103

Chaiken, S., \& Trope, Y. (1999). Dual-process theories in social psychology. New York: Guilford Press.

Cheung, M. (2010). The globalization and localization of persuasive marketing communication: A cross-linguistic socio-cultural analysis. Journal of Pragmatics, 42(2), 354-376. http://doi.org/10.1016/j.pragma.2009.06.012

Chomsky, N. (1965). Aspects of the theory of syntax. Massachussetts, Cambridge, USA: M.I.T. Press. 
Cloutier, M., Ladouceur, R., \& Sévigny, S. (2006). Responsible gambling tools: Pop-up messages and pauses on video lottery terminals. The Journal of Psychology, 140(5), 434-438.

Ejova, A., Delfabbro, P. H., \& Navarro, D. J. (2013). Erroneous gambling-related beliefs as illusions of primary and secondary control: a confirmatory factor analysis. Journal of Gambling Studies, 31(1), 133-60. http://doi.org/10.1007/s10899-013-9402-9

Floyd, K., Whelan, J. P., \& Meyers, A. W. (2006). Use of warning messages to modify gambling beliefs and behavior in a laboratory investigation. Psychology of Addictive Behaviors, 20(1), 69-74. http://doi.org/10.1037/0893-164X.20.1.69

Fodor, J. A. (1983). The modularity of mind: An essay on faculty psychology. Cambridge: MIT press.

Fodor, J. A., \& Garrett, M. F. (1967). Some syntactic determinants of sentential complexity. Perception \& Psychophysics, 2(7), 289-296. http://doi.org/10.3758/BF03211044

Fortune, E. E., \& Goodie, A. S. (2012). Cognitive distortions as a component and treatment focus of pathological gambling: A review. Psychology of Addictive Behaviors, 26(2), 298-310. https://doi.org/10.1037/a0026422

Ferland, F., Ladouceur, R., \& Vitaro, F. (2005). Efficacité d'un programme de prévention des habitudes de jeu chez les jeunes: Résultats de l'évaluation pilote [Effectiveness of a Youth Play Prevention Program: Results of the Pilot Evaluation]. L'Encéphale, 31, $427-436$.

Gallagher, K. M., \& Updegraff, J. A. (2012). Health Message Framing Effects on Attitudes, Intentions, and Behavior: A Meta-analytic Review. Annals of Behavioral Medicine, 43(1), 101-116. https://doi.org/10.1007/s12160-011-9308-7

Gallardo, S. (2005). Pragmatic support of medical recommendations in popularized texts. Journal of Pragmatics, 37(6), 813-835. http://doi.org/10.1016/j.pragma.2004.10.013 
Grice, H. P. (1975). Logic and Conversation. In P. Cole \& J. L. Morgan, Syntax and Semantics (Vol. 3, p. 41-58). New York: Academic Press.

Hammond, D., Fong, G. T., Mc Neill, A., Borland, R., \& Cummings, K. M. (2006). Effectiveness of cigarette warning labels in informing smokers about the risks of smoking: findings from the International Tobacco Control (ITC) Four Country Survey. Tobacco Control, 15(3), 19-25. http://doi.org/10.1136/tc.2005.012294

Jardin, B., \& Wulfert, E. (2009). The Use of Messages in Altering Risky Gambling Behavior in College Students: An Experimental Analogue Study. American Journal on Addictions, 18(3), 243-247. http://doi.org/10.1080/10550490902786918

Johnson-Laird, P. N. (1977). Psycholinguistics without linguistics. In N. S. Sutherland, Tutorial essays in psychology. Hillsdale, N.J.: Erlbaum.

Johnson-Laird, P. N. (1983). Mental Models: Towards a Cognitive Science of Language, Inference, and Consciousness. Cambridge: Cambridge University Press.

Joukhador, J., Maccallum, F., \& Blaszczynski, A. (2003). Differences in cognitive distortions between problem and social gamblers. Psychological Reports, 92(3), 1203-1214. http://doi.org/10.2466/pr0.2003.92.3c.1203

Juanico, R., \& Myard, J. (2017). Evaluation de la régulation des jeux d'argent et de hasard [Evaluation of the regulation of gambling] (Rapport d'information No. 4456). Enregistré à la Présidence de l'Assemblée nationale: Assemblée Nationale - Comité d'évaluation et de contrôle des politiques publique.

Kim, H. S., Wohl, M. J. A., Stewart, M. J., Sztainert, T., \& Gainsbury, S. M. (2014). Limit your time, gamble responsibly: setting a time limit (via pop-up message) on an electronic gaming machine reduces time on device. International Gambling Studies, 14(2), 266-278. https://doi.org/10.1080/14459795.2014.910244 
Kouabenan, D. R., \& Ngueutsa, R. (2015). Control beliefs and engagement in hygienic and safety behaviours: the case of foodborne illness. International Journal of Environmental Health Research, 1-15. http://doi.org/10.1080/09603123.2015.1119807

Ladouceur, R., \& Walker, M. (1996). A cognitive perspective on gambling. In Trends in cognitive and behavioural therapies (Wiley, p. 89-120). Oxford: Salkovskis P. M.

Langer, E. J. (1975). The illusion of control. Journal of personality and social psychology, $32(2), 311-328$.

Laughery, K. R., \& Wogalter, M. S. (2014). A three-stage model summarizes product warning and environmental sign research. Safety Science, 61, 3-10. http://doi.org/10.1016/j.ssci.2011.02.012

Le Floch, V. (2008). Plausibility judgment of causally related social events: Impact of conceptual coherence and word-coherence. Journal of Pragmatics, 40(7), 1202-1215. http://doi.org/10.1016/j.pragma.2008.01.002

Martinez, F., Le Floch, V., Gaffié, B., \& Villejoubert, G. (2011). Reports of wins and risk taking: An investigation of the mediating effect of the illusion of control. Journal of Gambling Studies, 27(2), 271-285. http://doi.org/10.1007/s10899-010-9204-2

May, R. K., Whelan, J. P., Meyers, A. W., \& Steenbergh, T. A. (2005). Gambling-related Irrational Beliefs in the Maintenance and Modification of Gambling Behaviour. International Gambling Studies, 5(2), 155-167. http://doi.org/10.1080/14459790500303147

Meyer, G., Hayer, T., \& Griffiths, M. D. (2009). Problem gambling in Europe: Challenges, Prevention and Intervention. New York: Springer.

Monaghan, S. (2009). Responsible gambling strategies for Internet gambling: The theoretical and empirical base of using pop-up messages to encourage self-awareness. Computers in Human Behavior, 25(1), 202-207. https://doi.org/10.1016/j.chb.2008.08.008 
Monaghan, S., \& Blaszczynski, A. (2010). Impact of mode of display and message content of responsible gambling signs for electronic gaming machines on regular gamblers. Journal of Gambling Studies, 26(1), 67-88. https://doi.org/10.1007/s10899-009-9150$\mathrm{Z}$

Myrseth, H., Brunborg, G. S., \& Eidem, M. (2010). Differences in cognitive distortions between pathological and non-pathological gamblers with preferences for chance or skill games. Journal of Gambling Studies, 26, 561-569. http://doi.org/10.1007/s10899010-9180-6

O’Neil, K. M., Penrod, S. D., \& Bornstein, B. H. (2003). Web-based research: Methodological variables' effects on dropout and sample characteristics. Behavior Research Methods, Instruments, \& Computers, 35(2), 217-226. http://doi.org/10.3758/BF03202544

Papineau, E., Boisvert, Y., Chebat, J.-C., \& Suissa, A. J. (2012). La commercialisation des loteries au Québec: Modalités, impacts et implications sociales et de santé publique [The marketing of lotteries in Québec: Social and public health conditions, impacts and implications] (Report No. 2010-JC-136938). Québec: Institut National de Santé Publique du Québec.

Parke, A., Harris, A., Parkes, J., Rigbye, J., \& Blaszczynski, A. (2015). Facilitating player control in gambling. The Journal of Gambling Business and Economics, 8(3), 36-51.

Petty, R. E., \& Cacioppo, J. T. (1986). The elaboration likelihood model of persuasion. Advances in Experimental Social Psychology, 19, 123-205. http://doi.org/10.1016/S0065-2601(08)60214-2

Ratcliff, J. E. (1987). The plausibility effect: Lexical priming or sentential processing? Memory \& cognition, 15(6), 482-496. http://doi.org/10.3758/BF03198382 
Rogers, W. A., Lamson, N., \& Rousseau, G. K. (2000). Warning research: An integrative perspective. Human Factors: The Journal of the Human Factors and Ergonomics Society, 42(1), 102-139. http://doi.org/10.1518/001872000779656624

Rothman, A. J., Bartels, R. D., Wlaschin, J., \& Salovey, P. (2006). The Strategic Use of Gainand Loss-Framed Messages to Promote Healthy Behavior: How Theory Can Inform Practice. Journal of Communication, 56(s1), S202-S220. http://doi.org/10.1111/j.14602466.2006.00290.x

Rothman, A. J., \& Kiviniemi, M. T. (1999). Treating people with information: an analysis and review of approaches to communicating health risk information. JNCI monographs, 25, $44-51$.

Song, A. V., Morrell, H. E. R., Cornell, J. L., Ramos, M. E., Biehl, M., Kropp, R. Y., \& Halpern-Felsher, B. L. (2009). Perceptions of Smoking-Related Risks and Benefits as Predictors of Adolescent Smoking Initiation. American Journal of Public Health, 99(3), 487-492. http://doi.org/10.2105/AJPH.2008.137679

Sperber, D., \& Wilson, D. (1986). Relevance. Communication and Cognition (2nd éd.). Oxford: Blackwell.

Steenbergh, T. A., Whelan, J. P., Meyers, A. W., May, R. K., \& Floyd, K. (2004). Impact of warning and brief intervention messages on knowledge of gambling risk, irrational beliefs and behaviour. International Gambling Studies, 4(1), 3-16. https://doi.org/10.1080/1445979042000224377

Tannenbaum, M. B., Hepler, J., Zimmerman, R. S., Saul, L., Jacobs, S., Wilson, K., \& Albarracín, D. (2015). Appealing to fear: A meta-analysis of fear appeal effectiveness and theories. Psychological Bulletin, 141(6), 1178-1204.

https://doi.org/10.1037/a0039729 
Wänke, M. (2007). What is said and what is meant: Conversational implicatures in natural conversations, research settings, media and advertising. In K. Fielder, ed. Social communication. New York: Psychology Press, 223-256.

Weiner, B., Osborne, D., \& Rudolph, U. (2011). An Attributional Analysis of Reactions to Poverty: The Political Ideology of the Giver and the Perceived Morality of the Receiver. Personality and Social Psychology Review, 15(2), 199-213. http://doi.org/10.1177/1088868310387615

Wohl, M. J. A., Christie, K.-L., Matheson, K., \& Anisman, H. (2010). Animation-Based Education as a Gambling Prevention Tool: Correcting Erroneous Cognitions and Reducing the Frequency of Exceeding Limits Among Slots Players. Journal of Gambling Studies, 26(3), 469-486. https://doi.org/10.1007/s10899-009-9155-7

Wood, R. T. A., \& Wohl, M. J. A. (2015). Assessing the effectiveness of a responsible gambling behavioural feedback tool for reducing the gambling expenditure of at-risk players. International Gambling Studies, 15(2), 1-16. https://doi.org/10.1080/14459795.2015.1049191

\section{Conflict of interest}

Funding sources

AM received a grant from the French Interdepartmental Mission for the Fight against Addictive Behaviors (MILDECA) and the School of Advanced Studies in Social Sciences (EHESS).

\section{Competing interests}

The agencies approved the research questions, but had no involvement in the research design, methodology, conduct, analysis or write-up. Sponsors did not influence the design of the 
study or the way it was carried out. CL and JP received grant from agencies that have no links with gambling. The authors reported no competing interests.

\section{Constraints on publishing}

There were no constraints on publishing.

Disclosure statement

No potential conflict of interest was reported by the authors.

\section{Notes on contributors}

Aurélie Mouneyrac is a PhD student in psychology at the University of Toulouse. She works on the effects of misunderstandings in prevention campaigns on health behaviors. The present paper is the first of her $\mathrm{PhD}$ program.

Valérie Le Floch is a professor of social psychology. She studies risk-taking and decisionmaking in the context of social cognition and the plausibility of causal explanations. This study benefits from her expertise in models of conversational pragmatics.

Céline Lemercier is a professor of cognitive psychology and ergonomics, and an expert in the study of attention in complex human activities. She believes that the present study constitutes the first step that will lead to other studies focusing on the effect of the perceptual characteristics of prevention messages on gambling behavior.

Jacques Py is a professor of social psychology. His research focuses on decision- making, normative foresight, eyewitness testimony and professional training. His expertise is particularly oriented toward linking research and practice.

Maxime Roumegue is a psychologist and a cognitive ergonomist. This study was part of his formation in psychology for the master's degree. 